\title{
Essential components of a successful doctoral program in nanomedicine
}

\author{
This article was published in the following Dove Press journal: \\ International Journal of Nanomedicine \\ 19 December 2014 \\ Number of times this article has been viewed
}

\author{
Anne $L$ van de Ven ${ }^{1,2}$ \\ Mary H Shann ${ }^{3}$ \\ Srinivas Sridhar ${ }^{1,2}$ \\ 'Nanomedicine Science and \\ Technology Center, ${ }^{2}$ Department \\ of Physics, Northeastern University, \\ Boston, MA, USA; ${ }^{3}$ School \\ of Education, Boston University, \\ Boston, MA, USA
}

\begin{abstract}
The Nanomedicine program at Northeastern University provides a unique interdisciplinary graduate education that combines experiential research, didactic learning, networking, and outreach. Students are taught how to apply nanoscience and nanotechnology to problems in medicine, translate basic research to the development of marketable products, negotiate ethical and social issues related to nanomedicine, and develop a strong sense of community involvement within a global perspective. Since 2006, the program has recruited 50 doctoral students from ten traditional science, technology, and engineering disciplines to participate in the 2-year specialization program. Each trainee received mentoring from two or more individuals, including faculty members outside the student's home department and faculty members at other academic institutions, and/or clinicians. Both students and faculty members reported a significant increase in interdisciplinary scholarly activities, including publications, presentations, and funded research proposals, as a direct result of the program. Nearly $90 \%$ of students graduating with a specialization in nanomedicine have continued on to careers in the health care sector. Currently, $43 \%$ of graduates are performing research or developing products that directly involve nanomedicine. This article identifies some key elements of the Nanomedicine program, describes how they were implemented, and reports on the metrics of success.
\end{abstract}

Keywords: nanomedicine, IGERT, nanotechnology, nanoscience, education, graduate training

\section{Introduction}

There is a growing need for formal training in nanomedicine. Since 2003, the National Institutes of Health $(\mathrm{NIH})$ has recognized the field of nanomedicine in its Roadmap for Medical Research. ${ }^{1}$ In 2007, the strategic plan of the US National Nanotechnology Initiative identified training of a workforce skilled in the application of nanotechnology for public benefit as a primary goal. ${ }^{2}$ In 2009, the US Bureau of Labor Statistics projected that employment at the interface of medicine, science, and engineering will grow $72 \%$ by $2018,{ }^{3}$ making this the fastest-growing occupation in the US. Personalized health care and diagnostics, another area in which nanomedicine is poised to play a major role, was recently identified as one of 14 focus areas awaiting engineering solutions in the 21 st century by the US National Academy of Engineering. ${ }^{4}$ Over the past decade, both the US and the European Union have committed funds toward the establishment of collaborative research centers in nanomedicine. Academic institutions now have a unique opportunity to play a formative role in the education and training of future leaders in nanomedicine..$^{5-7}$

The Nanomedicine program at Northeastern University, which was established in 2005 and competitively renewed in 2010, is an example of a successful doctoral-level training program in nanomedicine. Established in response to a call from the National 
Science Foundation (NSF) to develop broad-based graduate education programs centered on an interdisciplinary research theme, participants in this 2-year specialization program receive training in nanomedicine while continuing to acquire deep knowledge in their chosen doctoral field. Here we identify the key elements of this Integrative Graduate Education and Research Traineeship (IGERT) program, describe the benefits and challenges of its implementation, and report on early outcomes that can be considered metrics of success.

\section{Implementation}

The Nanomedicine program at Northeastern University aims to enrich the graduate experience of doctoral students in traditional science, technology, engineering, and mathematics (STEM) disciplines through supplemental education and training in nanomedicine. Given the highly interdisciplinary nature of nanomedicine, faculty members at the Northeastern University set out to provide students with the skills necessary for applying nanoscience and nanotechnology to problems in medicine, while simultaneously fostering the business, ethical, and global perspectives needed for a successful career in nanomedicine. To implement our program goals, we established a curriculum that combines experiential research, didactic learning, networking, and outreach (Table 1). Activities specifically developed for the Nanomedicine program include specialized courses, a weekly seminar series, formalized co-mentoring for each student, an internship requirement, and outreach activities. To ensure that participants acquire depth of knowledge in their core competency, students continue to complete all degree requirements and defend a dissertation in their home department.

Four new interdisciplinary core courses were developed (Table 2). Nanomedicine (NNMD) 5270 introduces students from a broad range of disciplines to science and engineering concepts important in nanomedicine. Through a 50/50 combination of lectures and guest symposia, students are taught the fundamentals of nanoscience and nanotechnology, followed by firsthand accounts of how they can be applied to problems in medicine. The NNMD 7370 techniques course provides students with an in-depth look at fundamentals of nanomedicine, research methods, and instrumentation, with the goal of lowering barriers to trying new techniques and giving students a broader range of research options for their thesis work. To train students at the detail level needed for independence, students learn the tricks of the trade in a hands-on manner from postdoctoral scholars and senior technicians under the oversight of a course instructor. The NNMD 5470 commercialization course teaches students how to take ideas in nanomedicine, nanotechnology, and

Table I Strategies for graduate education in nanomedicine

\begin{tabular}{|c|c|}
\hline Program goals for trainees & Implementation strategies \\
\hline \multirow[t]{2}{*}{ Depth of knowledge } & Coursework in STEM discipline \\
\hline & Dissertation in STEM discipline \\
\hline \multirow[t]{2}{*}{ Breadth of knowledge } & Coursework in nanomedicine \\
\hline & Seminar series in nanomedicine \\
\hline \multirow[t]{3}{*}{ Interdisciplinary research skills } & Mentored research project in nanomedicine \\
\hline & Internal co-mentoring \\
\hline & External co-mentoring and/or academic internship \\
\hline \multirow[t]{5}{*}{ Communication and teamwork } & Coursework with feedback on writing and presentation skills \\
\hline & Publication of peer-reviewed manuscripts \\
\hline & Presentation at academic/professional conferences \\
\hline & Networking luncheons \\
\hline & Informal retreats and group meetings \\
\hline \multirow[t]{3}{*}{ Nonacademic career preparation } & Coursework in commercialization \\
\hline & Coursework in career skills \\
\hline & Internship in industry, medicine, or government \\
\hline \multirow[t]{2}{*}{ Outreach } & Individual and team-driven outreach opportunities \\
\hline & Participation in mentoring of high school and undergraduate students \\
\hline \multirow[t]{4}{*}{ Expansion of international perspective } & Collaboration with foreign colleagues inside US \\
\hline & Collaboration with foreign colleagues outside US \\
\hline & Internships outside the US \\
\hline & Attendance at international conferences \\
\hline \multirow[t]{2}{*}{ Broadening participation of underrepresented groups } & Recruitment of trainees from minority-serving institutions \\
\hline & Interactive class broadcast to minority-serving institutions \\
\hline
\end{tabular}

Abbreviation: STEM, science, technology, engineering, and mathematics. 
Table 2 Course offerings in nanomedicine

\begin{tabular}{|c|c|c|}
\hline & Courses & Content \\
\hline NNMD 5270 (3 SH) & $\begin{array}{l}\text { Introduction to Nanomedicine Science } \\
\text { and Technology }\end{array}$ & $\begin{array}{l}\text { Lectures and symposia on the application of nanoscience } \\
\text { and nanotechnology to problems in medicine }\end{array}$ \\
\hline NNMD 7370 (2-5 SH) & $\begin{array}{l}\text { Nanosystems Design for Biology } \\
\text { and Medicine }\end{array}$ & $\begin{array}{l}\text { Hands-on training in theory, research methods, } \\
\text { and instrumentation }\end{array}$ \\
\hline NNMD 5470 (3 SH) & $\begin{array}{l}\text { Bio/Nano Product Development: } \\
\text { From Concept to Market }\end{array}$ & $\begin{array}{l}\text { Lectures and symposia on fundamental concepts for R\&D, market } \\
\text { evaluation, raising capital, protecting intellectual property, regulatory } \\
\text { affairs, and building a thriving business }\end{array}$ \\
\hline NNMD 7272 (I SH) & Nanomedicine Seminar & $\begin{array}{l}\text { Symposia and networking events with nanomedicine experts based } \\
\text { in hospitals, businesses, industry, and other academic institutions }\end{array}$ \\
\hline
\end{tabular}

Abbreviations: NNMD, Nanomedicine; R\&D, research and development; SH, student hours.

pharmaceutical sciences from the concept level to the market level. Like NNMD 5270, a combination of lectures and symposia is used to expose students to a wide variety of firsthand accounts from venture capitalists, entrepreneurs, corporate leaders, and regulatory officials. To round out the course offerings, students are required to attend the weekly NNMD 7272 seminar series for 2 years. On average, 15-20 symposia are hosted at Northeastern University each year, with guest speakers drawn from hospitals, businesses, industry, and other academic institutions. Students in the Nanomedicine program are provided dedicated time to network with each speaker, either before or after each symposium.

$\mathrm{PhD}$ students admitted into the program are expected to pursue a mentored research project in nanomedicine. For some students, this is a continuation of their primary thesis project; for others, this is an opportunity to develop a new secondary research direction. Applicants must commit $\geq 50 \%$ of their research time to a Nanomedicine project in order to qualify. As part of the competitive application process, each potential trainee defends a research proposal in front of a committee of nanomedicine experts who are responsible for judging the suitability of the project, suggesting improvements to the experimental design, and identifying areas where the student would benefit from additional mentorship. This early guidance serves as a first step in teaching the students how to select and solicit advice from multiple mentors. Each student's research plan is designed so that it can be conducted from at least two different perspectives within different laboratories, and if appropriate, via an internship as well. During the research phase, trainees are required to meet regularly with at least two preapproved faculty mentors. While the overall structure of each trainee-mentor relationship and the degree of guidance received varies from student to student, trainees are expected to formally meet with their co-mentors at least once quarterly. This dual mentor model is the key for providing Nanomedicine students with an interdisciplinary training and research environment.

Trainees are highly encouraged to participate in a nonacademic internship to broaden their career horizons. Given the diverse research interests of program participants, no formal placement program has been implemented. Instead, students are asked to use their own initiative and seek help from their mentors to identify appropriate internship opportunities. Students are made aware of this expectation at the program start in order to provide sufficient time for identifying an internship that will benefit their training with minimal disruption to their research progress. Of the Nanomedicine curriculum components, the internship requirement has proven the most difficult to implement. Although the program funds internships in nonacademic institutions, few students have taken advantage of this. The idea of an off-campus internship is appealing to many students, but the overall time required away from their dissertation research is generally more than most students are comfortable with. As a result, there is a high propensity for trainees to perform internships in the laboratories of their academic collaborators, either at Northeastern University or at local universities/hospitals.

Nanomedicine students round out their training through involvement in $\mathrm{K}-12$ education. Each year, the Nanomedicine program provides trainees with access to a variety of individual and team-based outreach opportunities, including teaching in $\mathrm{K}-12$ public schools, developing workshops for visiting students, mentoring high school students in the laboratory, and judging local science fairs. Trainees are expected to participate for a minimum of 40 hours, with the goal of promoting communication, teamwork, teaching, mentoring, and leadership skills. Follow-up trainee interviews indicate a high level of satisfaction with this outreach aspect of the training program.

Several levels of program evaluation have been implemented to ensure that 1) the trainees comply with program 
requirements, 2) the program meets trainee expectations, and 3 ) the program is sufficiently flexible to adapt to trainee needs. Trainees provide yearly progress reports that document their coursework, research, internship, and outreach activities. An oversight committee evaluates trainee progress and ensures that each research project satisfies nanomedicine criteria. If a trainee's progress is unsatisfactory, the oversight committee may recommend changes to the trainee's program. Additionally, each trainee is surveyed and interviewed yearly in a small group setting by an external evaluator. These external reports are used to identify evolving issues and assess the responsiveness of the program administration to these issues.

\section{Trainee recruitment and retention}

Nanomedicine trainees are recruited from traditional STEM disciplines. Participants are chosen in a highly competitive process from among those already admitted to doctoral programs at Northeastern University. Selection criteria include research proposal quality and relevance, scholastic ability, motivation, and professional accomplishments. Students admitted into the program receive a 2-year fellowship, with the expectation that they will complete all program requirements in this time frame. To increase participation of underrepresented minorities, the program was expanded in 2010 to include students at the University of Puerto Rico at Mayaguez, and Tuskegee University in Alabama. Trainees at these locations perform research and receive mentoring at their home institution while participating in live, Web-based interactive courses and seminar broadcasts.

The Nanomedicine program has recruited 50 doctoral students (2006-2014) from ten different departments, including two unique to our partner institutions (Table 3 ). The program's commitment toward diversity is exemplified by the fact that $54 \%$ of trainees are women and $22 \%$ are underrepresented minorities. The national standard for IGERT programs is 36\% women and 7\% underrepresented minorities. ${ }^{8}$ In the first 5 years of the program, trainees were competitively selected from among students who had already completed their PhD candidacy. From 2010 onward, students were admitted as early as 1 year into their doctoral program. This change was in response to requests by trainees, who expressed a preference to complete the program requirements (particularly coursework) earlier in their graduate studies. This change was perceived to be advantageous from a programmatic perspective as well because it was likely to encourage students to commit more effort toward their Nanomedicine project (as opposed to other projects initiated before the fellowship) and to continue their Nanomedicine project after program completion. The first entrants into the program came primarily from the Biology, Chemistry, Pharmaceutical Sciences, and Physics courses. As the engineering programs at Northeastern University became more multidisciplinary, combined with expanded recruitment activities, we observed increased representation from students of Bioengineering and Chemical Engineering. To date, the program has enrolled trainees from ten departments in three universities. The retention rate of the program is $94 \%$ (with $6 \%$ of trainees completing a terminal MS degree), which is well above the $84 \%$ retention rate reported by the NSF for other IGERT programs. ${ }^{9}$ To date, $50 \%$ of trainees have completed their $\mathrm{PhD}$ and $44 \%$ are progressing toward their $\mathrm{PhD}$. The high percentage of students with work in progress reflects the fact that later trainees joined the Nanomedicine program earlier in their graduate studies.

\section{Outcomes}

The challenge of integrating students from diverse fields into a highly interdisciplinary program was accomplished

Table 3 Recruitment and retention of trainees from STEM disciplines

\begin{tabular}{|c|c|c|c|c|}
\hline Trainee department & Number recruited & PhD awarded & MS awarded & $\mathrm{PhD}$ in progress \\
\hline Bioengineering & 7 & 2 & I & 4 \\
\hline Biology & 4 & 3 & - & I \\
\hline Chemical Engineering & 6 & 2 & - & 4 \\
\hline Chemistry and Chemical Biology & 13 & 7 & - & 6 \\
\hline Electrical and Computer Engineering & 2 & I & - & I \\
\hline Integrated Biosciences* & I & - & - & I \\
\hline Mechanical and Industrial Engineering & 4 & 3 & - & I \\
\hline Materials Science and Engineering** & 2 & - & - & 2 \\
\hline Pharmaceutical Sciences & 9 & 6 & I & 2 \\
\hline Physics & 2 & 1 & 1 & - \\
\hline Total & 50 & 25 (50\%) & $3(6 \%)$ & 22 (44\%) \\
\hline
\end{tabular}

Notes: *Offered at University of Puerto Rico at Mayaguez only; **Offered at Tuskegee University only. Abbreviation: STEM, science, technology, engineering, and mathematics. 
Table 4 Trainee utilization of mentoring during their Nanomedicine research project

\begin{tabular}{ll}
\hline Sources of formal mentorship & $\begin{array}{l}\text { Number of } \\
\text { trainees }\end{array}$ \\
\hline Faculty members in home department & $44(88 \%)$ \\
Faculty members outside home department & $32(64 \%)$ \\
Clinicians and/or clinical researchers & $15(30 \%)$ \\
Faculty members at other academic institutions & $18(36 \%)$ \\
Professionals from other sectors (industry, government, etc) & $4(2 \%)$ \\
\hline
\end{tabular}

Note: $\mathrm{N}=50$.

through use of co-mentoring. Students were asked to select at least one scientific co-mentor during the application process; however, many took the initiative to cultivate additional mentors over the 2-year training period (Table 4). For the purposes of the program, a mentor was defined as an individual who 1) provided significant scientific guidance (as indicated by trainees in progress reports, meetings, or interviews) and 2) was listed as a contributor in at least one first-author manuscript prepared by the trainee. While there was a high tendency for students to have their primary Nanomedicine mentor in their home department $(88 \%$ of students), $80 \%$ of trainees also had at least one mentor outside of their department or institution. Notably, $30 \%$ of students had at least one clinician or clinical researcher as a mentor. These clinical mentors included representatives from local hospitals such as Dana-Farber Cancer Institute, Massachusetts General Hospital, Brigham and Women's Hospital, and Harvard Medical School, as well as several clinicians from other states. Many of these mentors were specifically acquired for the Nanomedicine projects and had not previously published together. In total, the research arm of the Nanomedicine program has brought together $>75$ mentors, including 38 from Northeastern University and 40 from outside institutions.

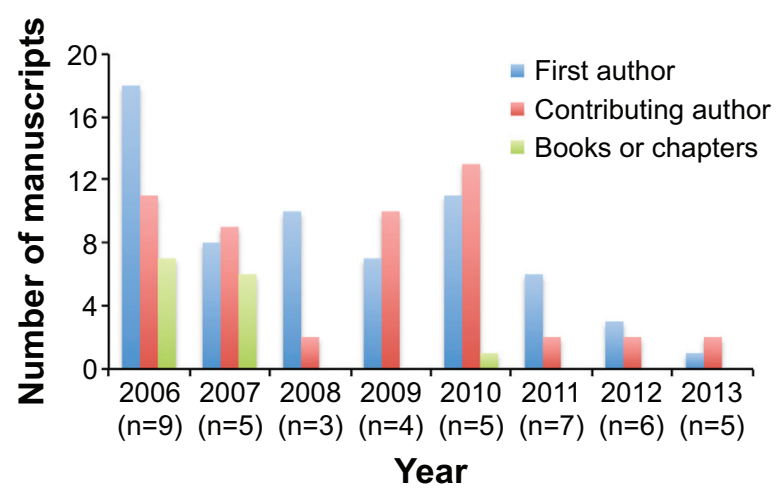

Given the large number of training activities organized by the Nanomedicine program, the students face a considerable challenge in balancing coursework, research, professional enrichment activities, and progress toward their dissertation. Thus the publication of manuscripts and the presentation of scientific data at conferences can be considered one metric of program success. Using a Web-based portal though which students provided yearly progress updates during and following training, we tracked the scientific output of each trainee (Figure 1). The trainees have published 117 peer-reviewed manuscripts and presented at 189 conferences to date. Students who graduated with a $\mathrm{PhD}$ produced an average of 3.9 manuscripts and 4.1 conference presentations directly related to their Nanomedicine project. When the statistics are compiled by the year of trainee entry into the program (Figure 1), the manuscript output is observed to be the highest for the years 2006-2010, when trainees were admitted later in their graduate studies. For the more junior students admitted after 2010, publications are now starting to emerge. The presentation of research findings, either through oral or poster presentations, has held relatively constant, at an average of $4.2 \pm 1.6$ presentations per student, likely due to the program's requirement for students to regularly participate in such events during the fellowship period.

The career paths of nanomedicine graduates were tracked through social media and personal communication (Table 5). Of the 28 trainees who have completed their terminal degree, 25 are pursuing careers in the health care sector, including in the fields of pharmaceuticals $(\mathrm{n}=8)$, diagnostics/biosensors $(n=8)$, molecular biology $(n=2)$, nanotherapeutics $(n=2)$, medical devices $(\mathrm{n}=2)$, public health education $(\mathrm{n}=2)$, and biotech/medical device patents $(n=1)$. Nearly half of those employed in health care are currently performing research or developing products that directly involve nanomedicine

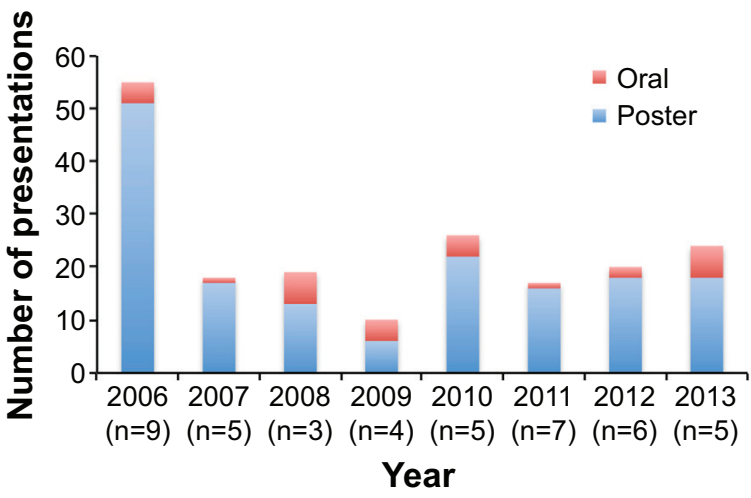

Figure I Academic achievements directly related to IGERT nanomedicine projects, sorted by year of trainee entry into the program. Abbreviation: IGERT, Integrated Graduate Education Research and Training. 
Table 5 Trainee career paths following graduation

\begin{tabular}{lll}
\hline Career path & $\begin{array}{l}\text { Health } \\
\text { care }\end{array}$ & $\begin{array}{l}\text { Health care, subset } \\
\text { nanomedicine }\end{array}$ \\
\hline Industry $(\mathrm{n}=12)$ & 12 & 4 \\
Academia $(\mathrm{n}=9)$ & 8 & 6 \\
Education $(\mathrm{n}=3)$ & 2 & - \\
Entrepreneurship $(\mathrm{n}=2)$ & 2 & 2 \\
Intellectual property $(\mathrm{n}=\mathrm{I})$ & $\mathrm{I}$ & - \\
Consulting $(\mathrm{n}=\mathrm{I})$ & - & - \\
Total $(\mathrm{N}=28)$ & $25(89 \%)$ & $12(43 \%)$ \\
\hline
\end{tabular}

(12 of 25). Those who have continued on to careers in nanomedicine have primarily pursued careers in academia (six of nine) or have started their own companies (two of two). Their ongoing nanomedicine projects include nanoparticle-based assays for bioanalyte detection $(n=6)$, nanoparticle-based biosensors ( $n=2)$, nanoformulation of pharmaceuticals $(n=3)$, and food packaging $(\mathrm{n}=1)$.

The Nanomedicine program has also had a significant impact at the faculty level. Faculty members of Northeastern University and partner institutions who participated as mentors for at least 1 year $(\mathrm{n}=38)$ were asked via a onetime yes/no survey about how the Nanomedicine program has directly affected their research (Table 6). Of the 25 respondents, $100 \%$ report that participation in the Nanomedicine program has enhanced their own interdisciplinary activities. Direct outcomes of the Nanomedicine program include manuscripts, conference presentations, and grant proposals prepared by the faculty members of different disciplines who had previously not worked together. These new collaborations were generally fruitful, with $84 \%$ of interdisciplinary collaborations leading to at least one quantifiable academic output.

Table 6 Program impacts on faculty activities*

\begin{tabular}{ll}
\hline $\begin{array}{l}\text { As a direct result of the Nanomedicine } \\
\text { program, I have }\end{array}$ & $\begin{array}{l}\text { Percentage of } \\
\text { faculty }(\mathbf{n}=\mathbf{2 5})\end{array}$ \\
\hline $\begin{array}{l}\text { Worked on projects with individuals outside my } \\
\text { home discipline }\end{array}$ & 96 \\
$\begin{array}{l}\text { Coauthored proposals with individuals outside } \\
\text { my home discipline }\end{array}$ & 84 \\
$\begin{array}{l}\text { Mentored students outside my home discipline } \\
\text { Participated on thesis committees outside my }\end{array}$ & 52 \\
home discipline \\
$\begin{array}{l}\text { Published research findings in journals outside } \\
\text { my home discipline }\end{array}$ & 68 \\
$\begin{array}{l}\text { Presented new research findings at conferences } \\
\text { outside my home discipline }\end{array}$ & 76 \\
Received new research grants, either singly or as \\
part of a team
\end{tabular}

Note: *As reported by faculty members who served as mentor for at least I year.

\section{Discussion}

The creation of a training program in Nanomedicine is highly challenging because this field attracts students from diverse disciplines and requires them to acquire both breadth and depth of knowledge to succeed in their chosen career path. At the time of program inception, we chose to implement a 2-year, cross-departmental fellowship program rather than a formal degree-granting program in order to 1) establish a large pool of potential students, 2) allow recruitment of faculty members with little to no interdisciplinary experience, and 3) ensure that trainees continue to acquire depth of knowledge in their chosen department. Thus, the program utilizes a "value-added" strategy to expand interactions across disciplines without diluting disciplinary credentials or the other benefits of membership in a single department.

We envisioned that such a specialization program will teach students how to integrate new knowledge, ideas, and skills from the perspective of two or more disciplines. The model we implemented was one of experiential research, didactic learning, networking, and outreach centered on a comprehensive nanomedicine theme. Students were exposed to a broad cross-section of researchers, clinicians, entrepreneurs, professionals, and civil servants through a combination of coursework and symposia. Opportunities for both formal and informal interactions were provided, including lunches, workshops, and internships, in order to expose the students to a variety of career paths and to enrich their understanding of the skills required for success. Strikingly, $89 \%$ of graduates pursued careers in health care, even though many of their home disciplines are not considered as traditional feeders for the health care sector. Graduates who chose careers in nanomedicine were successful in identifying a variety of career paths and were not limited to academia alone. Statistics suggest that the trainees understood their interdisciplinary training and that this training was sufficiently rigorous enough to prepare them for a career in nanomedicine.

With any such interdisciplinary program, there exists the potential for reduced productivity and increased difficulty in communication due to professional identity crisis. ${ }^{10,11}$ IGERT programs in other subject areas, including those at Arizona State University, ${ }^{12}$ Cornell University, ${ }^{13}$ Virginia Tech, ${ }^{14}$ and Drexel University/University of Pennsylvania, ${ }^{15}$ developed specialization programs to allow students to receive interdisciplinary training while pursuing a degree in their home discipline. The Nanomedicine program at Northeastern University implemented several strategies to proactively minimize the incidence of professional identity crises, including 1 ) providing trainees with formal training in nanomedicine terminology and experimental 
techniques, 2) allowing trainees to select projects and mentors within their comfort zone that fulfilled program criteria, 3) providing networking opportunities with both peers and potential mentors in different disciplines, 4) challenging trainees to educate others in nanomedicine via outreach activities, and 5) providing an outlet for continued knowledge acquisition in each trainee's chosen discipline. Trainees interviewed in focus groups by an external evaluator voiced few complaints about having to work or communicate outside of their field. For most students, their Nanomedicine research project coincided well with the direction of their thesis research.

In focus groups and one-on-one interviews, trainees acknowledged that the guidance and support of their primary advisor played a major role in shaping their academic, research, and internship experiences. But many trainees also noted that co-mentoring by faculty members from other disciplines broadened their thinking, and in particular, their approach to solving research challenges. This is in agreement with other successful IGERT programs, in which trainees reported more frequent interactions with mentors across departments. ${ }^{8}$ The broad range of mentors cultivated by nanomedicine trainees suggests that students successfully identified areas in their research that would benefit from additional mentorship. Given that faculty members identified as mentors participated in the publication of one or more manuscripts, it is likely that many of these mentors provided scientific guidance, access to new facilities and experimental techniques, or other forms of mentorship.

Faculty members who serve as mentors also benefit from the Nanomedicine program. Every faculty member who responded to our survey reported at least one new interdisciplinary activity as a direct outcome of program participation. When we consider the outcomes of the Nanomedicine program alone, apart from any other interdisciplinary activities, we observe that Nanomedicine mentors are more significantly more likely $(P<0.05)$ to perform research $(96 \%$ vs $78 \%$ ), publish $(80 \%$ vs $48 \%$ ), carry out presentations (76\% vs 44\%), and apply for grants (84\% vs 64\%) with colleagues across departments than faculty members who do not participate in interdisciplinary programs. ${ }^{9}$ The level of faculty involvement was highly similar to that reported by the faculty in other IGERT programs. ${ }^{9}$ While we would expect the Nanomedicine program to draw faculty members who are naturally inclined toward interdisciplinary research, we have also succeeded in attracting faculty with little to no prior nanomedicine experience. Because only $52 \%$ of faculty mentors report having mentored student(s) outside their home discipline, we believe that a significant proportion of these outcomes was the result of interdisciplinary projects initiated and driven by trainees themselves.

One of the most robust metrics for assessing the long-term viability of the program is research proposal funding. Excitingly, $56 \%$ of faculty members who submitted interdisciplinary proposals in Nanomedicine succeeded in obtaining funding. Notable examples include the NIH-funded Center for Translational Cancer Nanomedicine (NIH U54CA151881) and the 2010 multi-institutional IGERT Nanomedicine program expansion (NSF-DGE-0965843). Reports issued by the NSF indicate that participation in an IGERT program increases the likelihood of interdisciplinary funding by an average of $19 \%,{ }^{9}$ placing the Nanomedicine funding success rate well above average. Given that the federal funding infrastructure is still relatively limited for nanomedicine projects, we believe that the program has succeeded in establishing an environment conducive to nanomedicine research and training. This unique training environment is now being extended to undergraduates at Northeastern University through a 5-year Cancer Nanomedicine Co-ops for Undergraduate Research Experiences (CaNCURE) training program (NIH R25CA174650-02).

The success of the Nanomedicine program was made possible in part by its unique academic environment. Northeastern University's commitment to interdisciplinary scholarship and translational research resulted in institutional support at several levels, including 1) support at the executive level to fulfill the institution's vision statement, 2) support at the college level to foster cross-departmental collaboration, and 3) support at the faculty level to develop and champion a coherent program. We found the program applicants to be diverse, highly qualified, and motivated, which we attribute to the University's culture of experiential education and interdisciplinary research. Additionally, the proximity of Northeastern University to neighboring hospitals and medical schools including Massachusetts General Hospital, Harvard Medical School, and Dana-Farber Cancer Institute has allowed the program to attract highly motivated faculty mentors with clinical and basic research backgrounds. This unique academic environment, when combined with the programmatic elements described in detail above, have allowed Northeastern University to build a robust and dynamic Nanomedicine program with avenues for continued viability. As such, it is currently undergoing institutional review for expansion into a degree-granting $\mathrm{PhD}$ program.

\section{Conclusion}

The Nanomedicine program at Northeastern University is a well-established doctoral-level training program 
in nanomedicine. While it is difficult to define metrics of success for such a highly interdisciplinary program, we have identified several quantifiable outcomes we believe to be indicative of success. These include scholarly outputs, such as publications, presentations, and funded research proposals, as well as cross-departmental collaborations and trainee career trajectories. Both trainee and faculty participants appear to have developed a long-term interest in nanomedicine, as demonstrated by their propensity to pursue funding and careers in nanomedicine research. Additionally, the program has successfully recruited and retained underrepresented minorities at rates well above the national average. We believe that the success of the Nanomedicine program lies in a variety factors, including a well-defined curriculum that integrates research with focused education and training mechanisms; a combination of classroom, networking, and outreach activities for personal and professional enrichment; a highly motivated and diverse applicant pool; a highly active and diverse faculty mentor pool; and a supportive institutional environment.

\section{Acknowledgments}

This work was supported by the National Science Foundation (NSF) through Integrative Graduate Education and Research Traineeship (IGERT) grants NSF-DGE-0965843 and NSF-DGE-0504331 to Northeastern University. We thank Rita Kaderian for providing assistance with data collection. We also thank the IGERT program faculty members, staff, and trainees (see www.igert.neu.edu) for their central contributions to and for providing feedback on the program as described in this article.

\section{Disclosure}

The authors report no conflicts of interest in this work.

\section{References}

1. Zerhouni E. The NIH roadmap. Science. 2003;302(5642):63-72.

2. National Science and Technology Council. National Nanotechnology Initiative Strategic Plan. Washington, DC: National Science and Technology Council; 2007.

3. Lacey TA, Wright B. Occupational employment projections to 2018. Mon Labor Rev. 2009;132:82-99.

4. Committee on Science, Engineering, and Public Policy. Reshaping the Graduate Education of Scientists and Engineers. Washington, DC: National Academy of Sciences; 1995.

5. Murday JS, Siegel RW, Stein J, Wright JF. Translational nanomedicine: status assessment and opportunities. Nanomedicine. 2009;5(3):251-273.

6. Pautler M, Brenner S. Nanomedicine: promises and challenges for the future of public health. Int J Nanomedicine. 2010;5:803-809.

7. Velez JM, Velez JJ. The eminent need for an academic program in universities to teach nanomedicine. Int J Nanomedicine. 2011;6: 1733-1738.

8. Abt Associates Inc. Evaluation of the National Science Foundation's Integrative Graduate Education and Research Traineeship Program (IGERT): follow-up study of IGERT Graduates. National Science Foundation; 2011; Virginia, US.

9. Abt Associates Inc. Evaluation of the initial impacts of the National Science Foundation's Integrative Graduate Education and Research Traineeship Program. The National Science Foundation; 2006; Virginia, US.

10. Tsai-hsuan Ku S. Forming interdisciplinary expertise: one organization's journey on the road to translational nanomedicine. Wiley Interdiscip Rev Nanomed Nanobiotechnol. 2012;4(4):366-377.

11. Derrick EG, Falk-Krzesinski HJ, Roberts MR. Facilitating Interdisciplinary Research and Education: A Practical Guide. Washington, DC: American Association for the Advancement of Science; 2012.

12. Martin PE, Umberger BR. Trends in interdisciplinary and integrative graduate training: an NSF IGERT example. Quest. 2003;55(1):86-94.

13. Moslemi JM, Capps KA, Johnson MS, et al. Training tomorrow's environmental problem solvers: an integrative approach to graduate education. Bioscience. 2009;59(6):514-521.

14. Drezek KM, Olsen D, Borrego M. Crossing disciplinary borders: a new approach to preparing students for interdisciplinary research. Paper presented at: 38th Annual Frontiers in Education Conference; October 22-25, 2008; Saratoga Springs, NY.

15. Cowan K, Gogotsi Y. The Drexel/UPenn IGERT: creating a new model for graduate education in nanotechnology. J Mater Educ. 2004;26(1-3):147-152.
International Journal of Nanomedicine

\section{Publish your work in this journal}

The International Journal of Nanomedicine is an international, peerreviewed journal focusing on the application of nanotechnology in diagnostics, therapeutics, and drug delivery systems throughout the biomedical field. This journal is indexed on PubMed Central, MedLine, CAS, SciSearch ${ }^{\circledR}$, Current Contents ${ }^{\circledR} /$ Clinical Medicine,

\section{Dovepress}

Journal Citation Reports/Science Edition, EMBase, Scopus and the Elsevier Bibliographic databases. The manuscript management system is completely online and includes a very quick and fair peer-review system, which is all easy to use. Visit http://www.dovepress.com testimonials.php to read real quotes from published authors. 